\title{
CHILD ABUSE: LISTENING TO THE VOICES OF PRIMARY SCHOOL CHILDREN IN ALICE, EASTERN CAPE
}

\section{Tafadzwa Chinakidzwa, Merylyn Dika, Kgalalelo Rose Molefi, Evidence Prisca Mutasa, Nolufefe Yawathe, Nevashnee Perumal}

\section{INTRODUCTION: CONTEXTUAL FACTORS}

Child abuse is a global social "illness" which has led to numerous research studies being done in this area (Mersch, 2011). However, defining, understanding and intervening in child abuse are widely based on the perspective of adults, social service and health care practitioners, and academics (Chan, Lam \& Shae, 2011). It has also been noted that published studies done on this topic in South Africa have largely focused on urban experiences, although a large part of the South African population continues to live in villages, rural dwellings, homesteads and informal settlements (Jackson \& Karlson, 1991; Madu, 2001; Pierce \& Bozalek, 2004). Hence, this research study was conducted in the rural town of Alice by student social workers from the University of Fort Hare in an effort to listen to what primary school children understood about child abuse.

The Children's Act (Act No. 38 of 2005) is the national statutory tool that governs and protects all children in South Africa (South Africa, 2006). This Act defines a child as "any person under the age of 18 years". The Act defines "abuse in relation to a child, as any form of harm or ill treatment deliberately inflicted on a child and includes:

- Assaulting a child or inflicting any other form of deliberate injury to a child;

- Sexually abusing a child or allowing a child to be sexually abused;

- Bullying by another child;

- A labour practice that exploits a child;

- Exposing or subjecting a child to behaviour that may harm the child psychologically or emotionally" (South Africa, 2006:16).

According to Munro (2008:48), child abuse may further be specifically categorised as physical abuse, sexual abuse, emotional abuse and neglect. Physical abuse occurs when children experience broken limbs, bruises, cuts, burns and similar injuries resulting from intent on the part of an adult to cause physical harm or injury to a child. Emotional abuse is characterised by belittling a child by calling him/her derogatory names, using vulgar language to apportion blame or vent anger on a child, demoralising, victimising and threatening a child in ways which lead to reducing that child's self-esteem. Sexual abuse occurs when a child's sexual and reproductive organs are touched inappropriately, penetrated or sodomized by an adult for that adult's sexual gratification. It may also include exposing a child to sexual activity and pornography. Neglect occurs when a parent or responsible caregiver fails to provide adequate food, clothing, shelter and other basic needs for a child. Therefore the term "child abuse" refers to any action that endangers or impairs a child's physical, psychological, emotional and sexual development. 
Munro (2008:53) further indicates that in developed countries, abuse and neglect are regarded as a defect of parenting, which translates to an individual responsibility and failing. According to Schmid (2009:95), the gendered nature of Anglo-American discourse treats mothers and fathers differently, further "individualising" the responsibility of parenting. "Mothers" rather than "parents" bear the responsibility of keeping children safe and out of harm's way. This dynamic is evident in cases of child abuse, where the mother is viewed as uncaring and irresponsible if she does not ensure that the abuser (who may be her husband or boyfriend) is no longer part of the family. Hence it is a failing on the part of the mother to protect her children. In developing countries, such as South Africa, the majority of children and families known to child protection and welfare services are poor. Therefore banishing the "abuser", who is an income generator and provider, from the household may translate to a lack of much needed income in that household. This is a challenge that many households face, where keeping children safe from abuse is juxtaposed against having an income to feed those children (Munro, 2008; Rohner \& Rohner, 2002; Schwabe, 2006). These structural challenges, namely poverty, unemployment, lack of housing, political tensions and lack of basic services, are ideally issues that government must tackle, since the poor - whom these issues actually affect most seriously - are struggling with daily living ("bread and butter issues"). However, this is not the case as government is riddled with corruption, which in turn aggravates the conditions of the poor. Raising children with strained material resources and constant financial problems is therefore harder in povertystricken communities and rural, under-resourced communities than in affluent or middleclass communities. The community of Alice in the Eastern Cape fits this profile of a poor community, hence the relevance of this study.

The study was guided by the following key assumptions and theoretical frame of reference:

\section{Key assumptions}

- Primary school children, living and going to school in a rural town, may have little or no understanding of child abuse, its ramifications and ways to protect themselves when faced with abuse;

- Respect for elders and learning life's lessons from significant others, such as parents, elder siblings, grandparents and extended family shapes their futures.

\section{Theoretical framework}

The social learning theory propounded by Bandura (1994:71-81) underpinned this study. Social learning theory is based on the valuable notion that behaviour is learned through observation and modelling significant people in one's life. This theory has significance for the assumptions listed above, since children in rural communities depend largely on the "education" provided by their families when dealing with successes or challenges faced by families. Hence, for children this may translate into dealing with situations as elders do (modelling) (Bandura, 1994). Since adults in rural communities have greater problems to deal with such as poverty, HIV/AIDS and resource constraints, it follows logically then that abuse, neglect and gender-based violence may not be given priority in 
their lives as areas of concern (Perumal \& Kasiram, 2009). Rather these may be passed off as difficulties of daily living and therefore, according to social learning theory, children may learn from adults to ignore situations of abuse and neglect (Bandura, 1994).

The objectives of the research study were to:

- explore children's understanding of child abuse in the rural town of Alice;

- understand children's views on how to keep themselves safe from abuse;

- explore children's perceptions on the role of significant adults in their lives, pertaining to child abuse.

\section{RESEARCH APPROACH AND METHODOLOGY}

This study adopted a qualitative research approach, using descriptive and exploratory designs in order to understand children's insight into child abuse in Alice. Babbie and Mouton (2001:53) claim that qualitative studies provide a deeper understanding of and new insights into a research subject. According to Babbie and Mouton (2001:53), the aim of the qualitative approach is to "describe and understand not to explain and predict". According to Babbie and Mouton (2001:80), exploratory studies are most typically done to satisfy the researcher's curiosity and desire for better understanding as well as to test the feasibility of undertaking more extensive studies. In order to satisfy the researchers' curiosity and desire for a better understanding of children's perceptions of child abuse in the rural town of Alice in the Eastern Cape, the exploratory and descriptive designs were used. By using this qualitative research approach the researchers were able to explore what primary school children at the pre-adolescent stage of development, between the ages of eight and 11 years old, understood about child abuse and whether they were able to give meaning to this understanding by describing their experiences.

Since this study was aimed at gleaning the perceptions of children on child abuse, the participants were not specifically children who had experienced abuse and neglect.

Due to the limited number of primary schools in the town of Alice, one primary school was invited to participate in the study. A non-probability purposive sampling strategy was employed as there were clear criteria for the selection of participants:

"Non-probability purposive sampling is based entirely on the judgment of the researcher in that a sample is composed of elements that contain the most characteristics representative of typical attributes of the population" (Singerleton \& Straits, 1999:153).

Therefore the sample in this study had to be children, at the pre-adolescent stage of development, attending a primary school in Alice. In this study the children were between the ages of eight and 11 years, male and female, and attending a primary school in Alice. This age group was chosen because vulnerability depends, in part, on a child's age and gender. Since very young children are known to be more at risk of physical abuse and adolescent children are considered to be more at risk of sexual abuse and 
exploitation (World Health Organisation, 2002), children at the pre-adolescent stage of development were chosen as an in-between age group in this study to ascertain their understanding of child abuse.

Consent was obtained from the school principal to conduct the study at the school. Teachers in the grades from which participants were drawn assisted in identifying participants. Ten children from Grades 4 to 6, who were between the ages of eight and 11 years old, consented to participate. Written consent was obtained from both the participants and their parents. Although 10 participants consented, four of the participants withdrew from participating on the day of the focus group discussion. Therefore the final sample consisted of six participants.

A focus group was held with the participants. A focus group discussion was chosen for the following two reasons: the age of the participants and time constraints. It was anticipated that since the children were at the pre-adolescent stage of development, the participation of the children would be maximised in the supportive company of their peers; and since the study was being conducted during school hours, a focus group would reduce the time taken to gather data and the participants did not have to miss many lessons.

Although this focus group was guided by a semi-structured interview schedule, the researchers took specific note of the age of the children when determining the datacollection method. In the study conducted by Morgan, Gibbs, Maxwell and Britten (2002) on methodological issues in conducting focus groups with children, it was found that children between the ages of seven and 11 responded well to stimulus material within a focus group. The stimulus material in that study took the form of current television programmes and games that children were familiar with on the specific topic being researched (Morgan et al., 2002).

The researchers in this study attempted to use similar stimulus material such as a card game and DVD clip on abuse. Both these stimuli were created by the researchers themselves.

\section{The DVD clip on abuse}

The DVD depicted animated forms of abuse. The researchers selected various animations from current children's cartoons and formulated a two-minute visual presentation. Participants were then asked about the way the characters in the DVD dealt with the abuse. This gave the researchers the opportunity to spiral into the semistructured interview themes.

\section{The 15-second card game}

This game was played between two groups.

Cards numbered one to six were placed in a box. Participants were asked to pick a card. Those who picked even numbers formed one group and those who picked odd numbers formed another group. To play the game, another box of cards was used. These cards had one of the following written on each: parents, social worker, police, doctor, Alice Victim Support Centre (AVSC), psychologist and child welfare. Each group was given an opportunity to pick a card; fifteen seconds to deliberate the role and function of the person or organisation listed on their card; and fifteen seconds to explain the role of the 
person or organisation to everyone. After all the cards were picked, deliberated upon and explained, each group got an opportunity to choose a role that they would like to play in combatting child abuse. They were given 15 seconds to deliberate and 15 seconds to motivate their choice.

Rules of the game: Each team was given three seconds to start its presentation. Failure to do so resulted in the chosen card being awarded to the other team. The 15-second rule applied. Each team nominated a different speaker each time a card was chosen until all members had had a turn.

This game took approximately 20 minutes to complete.

These stimuli, which were aligned to the objectives of the study, generated qualitative discussion and enhanced confidence and rapport between the participants and researchers. This allowed for child-friendly data collection (Chan et al., 2011; Morgan et al., 2002; Punch, 2002). Authors such as Stafford, Laybourn, Hill and Walker (2003:361) attest that it is less intimidating for children to speak in a group than in a one-to-one interview with an adult researcher.

Data were analysed according to the circular nature of qualitative data analysis using the following four steps: coding, classifying, connecting and describing (Wildschut, 2007).

\section{The sample}

Six children participated in the study. Their profiles are reflected Table 1 . The small number of participants may be noted as a limitation; however, this number situated within the context of this study allowed the researchers to spiral into the interview themes, which enhanced the depth of discussions during the focus group (Strydom in De Vos, 2005:222-235). The interviews were conducted in English, since the medium of instruction in the school where the study was conducted is English.

\section{TABLE 1}

DEMOGRAPHIC PROFILE OF THE PARTICIPANTS

\begin{tabular}{|c|c|c|c|}
\hline Initial & Sex & Age & Grade \\
\hline R & F & 11 & 6 \\
\hline L & M & 8 & 4 \\
\hline A & M & 11 & 6 \\
\hline S & F & 10 & 6 \\
\hline S & F & 9 & 5 \\
\hline N & F & 9 & 5 \\
\hline
\end{tabular}

The participants were aged between eight and 11years. There were four female and two male participants. There was one participant from Grade 4, two participants from Grade 5 and three participants from Grade 6. 


\section{FINDINGS AND ANALYSIS}

The findings and analysis are presented according to themes generated from the overall objectives of the study.

\section{Theme 1: Perceptions of child abuse}

All participants acknowledged that they had heard or knew about child abuse. Participants indicated that they had witnessed child abuse situations either on television, or had personal experience of it at home or in the company of peers. One child responded as follows in response to the DVD presentation on child abuse:

"It brings back memories of when my father was beating my mother in 2004."

(L: Grade 4)

"It is when you are beaten for not doing anything wrong." (S: Grade 6)

Another participant related an incident where she witnessed a friend being sexually abused whilst they were going home from school.

"It is when someone is raped by a man like what happened to my friend when we were going home" [from school]. (A: Grade 6)

These incidents refer to emotional abuse experienced by these participants. As a result it may affect the child's development negatively. According to Rohner and Rohner (2002), emotional abuse from parents has consistent effects on the personality development of children such as hostility, aggression, an impaired sense of self-esteem and selfadequacy. According to social learning theory (Bandura, 1994:71-81), behaviour is learned through observation and modelling, which could manifest as the cycle of violence whereby the victim of abuse becomes the perpetrator.

Although one participant indicated that he may not want to repeat the cycle of abuse in adulthood as a result of witnessing abuse at home, this may be a premature deduction, but this goes beyond the scope of this study. This response is evident in the words of the participant who witnessed his father's abuse of his mother.

"This made me not to want to do the same when I grow up" (L: Grade 4).

\section{Children's definitions of child abuse}

The participants defined child abuse as follows.

TABLE 2

DEFINITIONS OF CHILD ABUSE

\begin{tabular}{|l|l|}
\hline Type of child abuse & Definitions \\
\hline Physical & Beatings that cause bruises and scars (R: Grade 6) \\
\hline Emotional & $\begin{array}{l}\text { Child abuse is emotional abuse or mental abuse [like being] bullied } \\
\text { at school. (L: Grade 4) }\end{array}$ \\
\hline Sexual & Rape, especially of girls (A: Grade 6) \\
\hline
\end{tabular}

The participants demonstrated different perceptions when defining child abuse. The participants defined child abuse as being of a physical, sexual or emotional nature. 
Definitions were based on what they had experienced, witnessed or seen on television. These responses were consistent with the definition of abuse provided in the Children's Act (South Africa, 2006:16), as cited in the Introduction.

Child abuse may be summarised as any form of harm or ill-treatment inflicted on a child. The Children's Act (South Africa, 2006:24) defines neglect in relation to a child as "a failure in the exercise of parental responsibilities to provide for the child's basic physical, intellectual, emotional or social needs." The definition by the participants indicates that children are knowledgeable about physical, sexual and emotional abuse. However, participants were less knowledgeable about neglect as a form of abuse and did not refer to it at all.

This study found that children's awareness of neglect as a form of abuse in Alice is affected by the South African environment in which they live (Bandura, 1994; Jackson \& Karlson, 1991). According to Munro (2008:49), neglect is considered as the inability or persistent failure to meet a child's basic physical and psychological needs. This may involve a parent or caregiver failing to provide adequate food, shelter and clothing (basic needs) for a child. Neglect, however, may also go beyond the provision of these basic physical needs. It may include a parent's or caregiver's inability to protect a child from physical harm or danger, failing to ensure access to appropriate medical care and treatment as well as an inability to meet a child's other basic needs such as a sense of belonging. Within the South African context generally and in the town of Alice and surrounding areas, the majority of families known to child protection and welfare services are poor. Hence, families may not be able to provide for a child's basic needs because of structural imbalances such as poverty and lack of health care facilities. Therefore, children may perceive neglect as normal and not as a form of abuse. Consequently, participants were unable to give responses on neglect. Daily living in South Africa is currently characterised by widespread poverty. Hence, lacking basic needs is the daily norm for the majority of the population (Schwabe, 2006).

The participants defined abuse in a way that parents, social service and health care practitioners might not have done. The definition of child abuse given by the participants appears to be defined according to what children see (signs) and directly linked to who the perpetrators are. This is similar to the findings by Chan et al. (2011) in a study conducted in Hong Kong which focused on children's views on child abuse and neglect. According to the study, some of the children's views on child abuse and neglect are uniquely their own and are markedly different from those of adults.

Moreover, a study conducted in Cape Town by Pierce and Bozalek (2004), which focused on child abuse in South Africa and examined how child abuse and neglect are defined, identified 17 categories of child maltreatment including child prostitution, child labour and child sexual abuse, while the research participants in this study only identified three categories of child maltreatment, namely sexual, physical and emotional.

It is possible therefore that participants have observed the conditions in their environment such as a lack of food or basic needs as normal and not as neglect. 
In the broader social context, referring to the care and protection of children and according to the Children's Act (Act No 38 of 2005), this may explain why a child may not understand why a social worker considers such conditions as grounds for removal and placement in alternative care, because that child has learnt to live in such conditions as normal (Perumal \& Kasiram, 2009).

Added to this, the community of Alice has children under the age of 17 receiving child support grants for their own children, yet no cases of statutory rape were ever reported on their behalf (Alice Victim Support Centre, 2010). Makiwane and Udjo (2006) indicate that teenage childbearing happens mostly outside marriage in South Africa and 20 per cent of teens who bear children are beneficiaries of the child support grant, whereas in most parts of sub-Saharan Africa, teen childbearing occurs in the context of early marriage.

This may indicate that teenage pregnancies are considered a normal and natural phenomenon, and not as sexual abuse of a child as defined by the South African Children's Act.

\section{Indicators of child abuse}

\section{TABLE 3}

INDICATORS OF ABUSE

\begin{tabular}{|l|l|}
\hline $\begin{array}{l}\text { Type of } \\
\text { abuse }\end{array}$ & \multicolumn{1}{c|}{ Indicators } \\
\hline Physical & Bruises and scars, torn clothes, scratches (R: Grade 6) \\
\hline Emotional & $\begin{array}{l}\text { Day dream[ing] in class(S: Grade 5) } \\
\text { Crying all the time (L: Grade 4) } \\
\text { Being alone from family members and friends at school (R: Grade 6) } \\
\text { Having lots of anger (A: Grade 6) }\end{array}$ \\
\hline Sexual & Rape [such] as bleeding, bruises, and cannot walk properly or sit (N: Grade 5) \\
\hline
\end{tabular}

Participants were knowledgeable about the indicators of the three major types of child abuse namely physical, emotional and sexual abuse. They referred to the indicators of child abuse as bruises and scars, poor concentration, crying all the time, being alone from family members and friends at school, lots of anger, unexplained bleeding, torn clothes, bruises, scratches and difficulty walking or sitting. Neglect was omitted. The participants were unable to give any indicators of neglect.

The related literature supports these findings. According to Hildyard and Wolfe (2002), physically abused children as well as neglected children have more severe cognitive and academic deficits as well as social withdrawal symptoms. In this study poor concentration may be considered an indicator of a cognitive deficit, which corresponds with Hildyard and Wolfe's (2002) findings. Participants in this study also identified social withdrawal and limited peer interactions such as being alone from family members and friends at school. This, according to Hildyard and Wolfe (2002), may have severe short- and long-term effects on children's cognitive, socio-emotional and behavioural development. 
Hildyard and Wolfe (2002) concur with Madu (2001), who pointed out some possible health and behavioural implications which matched the findings in this study, such as victims of such abuse daydreaming in class, crying all the time, being alone from family members and friends at school, and having lots of anger.

Hence, it may be concluded that the psychosocial and physical impact of child sexual abuse has far-reaching consequences for a child's development and progression into adulthood.

\section{Theme 2: Steps to be taken when abused}

Participants indicated that if they were to be abused, they would inform someone they trust, for example, a close friend, neighbours or someone not related to them such as community members or teachers at schools. This is captured in the following words:

"I would rather tell my neighbour because if I tell my mother she will not believe that my father is abusing me." (R: Grade 6)

"I will tell my teacher or my principal." (N: Grade 5)

"I will tell my friend." (A: Grade 6)

"I will call Childline or the police." (L: Grade 4)

The results support the findings by Chan et al. (2011) that children's disclosure of abuse in Hong Kong is often affected by loyalty to parents. On the other hand, some participants pointed out that they would inform the police or call the Childline toll-free number in order to seek assistance. The participants showed sound knowledge of the necessary steps to be taken in order to get help from the community organisations if necessary. This finding negated the researchers' assumption that children living and going to school in rural communities may have little or no knowledge of child abuse and where to seek help in such cases.

\section{Theme 3: Perpetrators of child abuse}

Participants identified parents, step-parents, siblings and fellow learners as the potential perpetrators of child abuse.

"Step-mothers and step-fathers are abusers." (N: Grade 5)

"Brothers also abuse younger brothers." (L: Grade 4)

"Parents abuse children when they beat them up for doing nothing wrong." (S: Grade 6)

"Children at school abuse other children when they tease or laugh at them." (A: Grade 6)

Participants indicated that people who abuse children are those who are close to them such as relatives and family members. In a study conducted in the Northern Province of South Africa on child sexual abuse and victim-perpetrator relationships Madu (2001) concluded that the majority of the perpetrators were acquaintances or relatives of the victims.

Some participants highlighted that peers may also be perpetrators of child abuse as this happens through bullying at school. According to the psychiatric theory of physical 
abuse, Jackson and Karlson (1991) confirm that children who are victims of abuse have certain abnormal personal characteristics and this leads to socially deviant behaviours manifesting as bullying of other children at school. Social learning theory also supports this finding (Bandura, 1994:71).

\section{Theme 4: Precautionary measures}

Some participants expressed violent measures as precautions against child abuse. These were:

"Pinching, fighting back, setting a trap" (S: Grade 6)

"Using bricks to throw at the abusers" (S: Grade 5)

"I will scream or shout" (L: Grade 4)

Another participant highlighted escaping as an option by stating:

"I will run away" (R: Grade 6)

This participant's view shows that she would opt to run away from the abuse, which in some cases leads to victims of abuse resorting to living on the streets.

On the other hand, other participants expressed that they would take appropriate positive action to act against child abuse. For instance, one respondent said that he would scream for help or call the police for help.

Participants did not identify any precautionary or preventative methods in order to keep themselves safe from abuse. However, they identified actions they would take if confronted with an abusive situation. They did not consider themselves living in an environment that could be harmful to them and did not have a need to actively engage in keeping themselves safe from abuse. They rather saw abuse as something that they can react to as opposed to being proactive about it.

\section{Theme 5: Roles of stakeholders}

TABLE 4

ROLE OF STAKEHOLDERS

\begin{tabular}{|c|l|l|l|}
\hline Parents & \multicolumn{1}{|c|}{ Teachers } & $\begin{array}{c}\text { Alice Victim } \\
\text { Support Centre } \\
\text { (AVSC) }\end{array}$ & $\begin{array}{c}\text { South African Police } \\
\text { Services (SAPS) }\end{array}$ \\
\hline - Help and guide & $\begin{array}{l}\text { - Listen } \\
\text { - Teach } \\
\text { - Refer to social } \\
\text { workers }\end{array}$ & $\begin{array}{l}\text { Investigate } \\
\text { matters of child } \\
\text { abuse }\end{array}$ & $\begin{array}{l}\text { - Respond to rape } \\
\text { - Protect the community } \\
\text { - Help you when teachers } \\
\text { or parents are abusive }\end{array}$ \\
\hline
\end{tabular}

The stakeholders identified were teachers, social workers, the Alice Victim Support Centre (AVSC) and the South African Police Services (SAPS). The stakeholders were seen to be there to protect children from harm. Ironically, though, participants identified parents as being there to help and guide, yet they were also identified as abusers and not trustworthy to disclose information to when a child is abused. This indicated that 
participants are aware of the perceived roles of adults, but in some cases this appeared to be different from their lived experiences.

It was also noted that children did not identify themselves as stakeholders in preventing abuse by engaging in precautionary measures in order to keep themselves safe.

\section{SUMMARY OF MAJOR FINDINGS AND RECOMMENDATIONS}

The major findings pointed to children in the rural town of Alice being aware of child abuse, the indicators of abuse and the actions to be taken when abused. However, key to this study's findings was the absence of neglect as a form of abuse. According to social learning theory (Bandura, 1994:71), it is possible that children internalise their living conditions and model the poverty-stricken conditions in which they live; therefore they do not consider a lack of basic needs and shelter as abuse. The researchers concluded that for many children neglect was part of their normal daily living because of the locale of the study.

Children identified reactions as opposed to proactive steps (preventative measures) and did not see themselves as primary stakeholders in preventing abuse.

The following recommendations were derived from a critical appraisal of the findings in this study.

\section{Children as partners and education on abuse}

Children in a rural town such as Alice are knowledgeable about child abuse and their views may be incorporated into the teaching and learning at school. This may be done in the Life Skills lessons at school, where children are given creative ways of expressing their views. for example, acting out a drama on child abuse and neglect followed by a class discussion, doing a poster presentation which may be displayed in a general area to enhance awareness on child abuse, or even replicating the 15-second card game used in this study.

The difference between abuse and discipline as well as child neglect must be clarified.

As highlighted in this study, the relatively low sensitivity of the children to child neglect and their reluctance to disclose abuse, especially sexual abuse, because of their loyalty to their parents, are areas to focus on in preventative child protection work in a South African community such as Alice. Children are not only victims in need of protection. They are also valuable partners with whom social service and health care practitioners should work closely.

\section{COMMUNITY ENGAGEMENT AND COLLABORATION}

Since the University of Fort Hare is situated in the heart of Alice and provides employment for many of the people in surrounding villages, a formal partnership between the University and schools in Alice needs to be forged. This will enable student social workers from the Department of Social Work and Social Development to take on an active role in providing knowledge, information, counselling and therapeutic work with children on abuse and neglect. It will further enable awareness programmes to be conducted with employees of the University, who have children in schools in Alice. 
These parents would be best placed to motivate other parents in the villages in which they live, to attend awareness programmes on prevention of child abuse and neglect. The communities surrounding Alice need to be made aware of the ripple effects of child abuse and neglect which impacts on the future of communities.

Collaborative partnerships between the Eastern Cape Departments of Education and Social Development need to be strengthened, so that both departments join forces and work towards keeping children safe from abusive situations, within the classroom and at home. Supportive and counselling services provided by the Department of Social Development need to be accessible to parents, since they need to be made aware of their role in actively protecting their children and the importance of forming supportive and nurturing relationships with their children. These may be conducted at grant collection points on grant day or at central points in the rural towns where the town's people converge for services.

\section{Future research}

There is a need for similar studies to be conducted in rural areas nationally in order to improve generalisations. More focused research should be conducted on child neglect in other rural communities such as Alice.

\section{REFERENCES}

ALICE VICTIM SUPPORT CENTRE (AVSC). 2010. Observation. Alice.

BABBIE, E. \& MOUTON, J. 2001. The practice of social research (South African edition). Cape Town: Oxford University Press Southern Africa.

BANDURA, A. 1994. Self-efficacy: Encyclopaedia of Human Behaviour (Vol. 4). New York: Academic Press, 71-81.

CHAN, Y. LAM, G.L.T. \& SHAE, W. 2011. Children's views on child abuse and neglect: findings from an exploratory study with Chinese children in Hong Kong. Child Abuse \& Neglect, 35(1):162-172.

Children's Act (Act No 38) of 2005, see South Africa, 2006.

DE VOS, A.S., STRYDOM, H., FOUCHÉ, C.B. \& DELPORT, C.S.L. 2005. Research at grass roots: for social sciences and Human Service Professions. South Africa: Van Schaik Publishers.

FRASER, S., LEWIS, V., DING, M., KELLETT, M. \& ROBINSON, C. (eds) 2003. Middle childhood: doing research with children and young people. London: Sage Publications.

HILDYARD, K.L. \& WOLFE, D.A. 2002. Child neglect: developmental issues and outcomes. Child Abuse and Neglect, 26(6-7):679-695.

JACKSON, J.W. \& KARLSON, H.C. 1991. Theories of child abuse and neglect: differential perspectives, summaries, and evaluations. [Online] Available: http://www.questia.com/ PM.qst?a=o\&d=10058973. [Accessed: 12/08/2011]. 
MADU, S.N. 2001. Childhood forcible sexual abuse and victim-perpetrator relationship among a sample of secondary school students in the Northern Province, South Africa. [Online] Available: http://www.crisa.org.za/downloads/ rape.pdf. [Accessed: 23/01/2011].

MAKIWANE, M. \& UDJO E. 2006. The Child Support Grant and teenage fertility in South Africa. [Online] Available: http://www.hsrc.ac.za/Document-2027.phtml. [Accessed: 08/08/2011].

MERSCH, J. 2011. Child abuse. [Online] Available: http://www.medicinenet.com/ child_abuse/article.htm. [Accessed: 10/07/2011.

MORGAN, M., GIBBS, S., MAXWELL, K. \& BRITTEN, N. 2002. Hearing children's voices: methodological issues in conducting focus groups with children aged 7-11 years. Qualitative Research, 2(1):5-20.

MUNRO, E. 2008. Effective child protection ( $\left.2^{\text {nd }} e d\right)$. London: Sage Publications.

PERUMAL, N. \& KASIRAM, M. 2009. Living in foster care and in a children's home: voices of children and their caregivers. Social Work/Maatskaplike Werk, 45(2):198206.

PIERCE, L. \& BOZALEK, V. 2004. Child abuse in South Africa: an examination of how child abuse and neglect are defined. Child Abuse \& Neglect, 28(8):817-832.

PUNCH, S. 2002. Interviewing strategies with young people: the 'secret box', stimulus material and task based activities. Children and Society, 16(1):45-56.

ROHNER, R.P. \& ROHNER, E.C. 2002. Antecedents and consequences of parental rejection: a theory of emotional abuse. [Online] Available: http://www.sciencedirect. com/science/article/pii/0145213480900071. [Accessed: 18/08 2011].

SCHWABE, C. 2006. Fact sheet: poverty in South Africa. [Online] Available: http://www. sarpn.org/documents/d0000990/ [Accessed: 18/08/2011].

SCHMID, J. 2009. Subjectivities in South African child welfare discourse. Transformation: Critical Perspectives on Southern Africa, 70:92-118.

SINGERLETON, R.A. (Jnr) \& STRAITS, B.C. 1999. Approaches to social research $\left(3^{\text {rd }}\right.$ ed). New York: Oxford University Press.

SOUTH AFRICA. 2006. Children's Act (Act No 38) of 2005. Government Gazette, 492(28944), June 19:1-217.

STAFFORD, A., LAYBOURN, A., HILL, M. \& WALKER, M. 2003. Having a say: children and young people talk about consultation. Children and Society, 17(5):361373.

WILDSCHUT, L. 2007. Qualitative data analysis: Module 5. Stellenbosch: University of Stellenbosch. 
208

WORLD HEALTH ORGANISATION. 2002. [Online] Available: http://www.who.int/ violence_injury_prevention. [Accessed 15/10/2012].

Ms Tafadzwa Chinakidzwa, Ms Merylyn Dika, Ms Kgalalelo Rose Molefi, Ms Evidence Prisca Mutasa, Ms Nolufefe Yawathe, (4th year student social workers); Mrs Nevashnee Perumal, Department of Social Work \& Social Development, University of Fort Hare, Alice, Eastern Cape, South Africa. 